\title{
Luis de León (1527-1591) y Su TeOría de la Justicia. Aspectos Principales de Su Doctrina ${ }^{1}$
}

\author{
Sebastián Contreras ${ }^{2}$
}

RESUMEN: Las investigaciones sobre Luis de León se han centrado, sobre todo, en su mística, narrativa y teoría literaria. En este trabajo, el autor intenta desarrollar los principales aspectos de su teoría jurídica. Al igual que otros grandes teólogos de la Escuela de Salamanca, también León ha estudiado el problema de la naturaleza de la ley humana y su vinculación con el derecho natural. Éste es, justamente, el tema del siguiente trabajo.

PALABRAS CLAVE: Luis de León. derecho natural. derecho positivo. Escuela de Salamanca. Segunda escolástica.

\section{AnTECEDENTES}

El estudio de los asuntos jurídicos se había hecho parte integrante de las investigaciones de los pensadores de la Neoescolástica del siglo $\mathrm{XVI}^{3}$. Esto no solamente entre los canonistas, sino también entre los teólogos y filósofos que seguían la tarea de renovación de la Escolástica medieval iniciada por Francisco de Vitoria. Prueba de ello son las palabras con que Domingo de Soto presenta su De Iustitia et Iure:

[...] nadie acuse a los teólogos de invadir una jurisdicción que sólo pertenece a los juristas, pues si el derecho canónico nació de las entrańas de la teología y el civil de la filosofía, es al teólogo a quien corresponde

\footnotetext{
${ }^{1}$ Este trabajo forma parte de una investigación más amplia patrocinada por FONDECYT-Chile, proyecto 3140035 .

${ }^{2}$ Facultad de Derecho. Universidad de los Andes, Chile. Álvaro del Portillo 12.455, Las Condes. E-mail: sca@miuandes.cl

${ }^{3}$ Para una revisión de las relaciones entre Filosofía, Teología y Derecho en las obras de los pensadores de la Escolástica renacentista: cf. SEELMANN, Kurt. Teologia e giurisprudenza alle soglie della Modernità. La nascita del moderno diritto naturale nella tarda scolastica iberica, en Materiali per una storia della cultura giuridica moderna, vol. 29, n. 2, p. 277-298, 1999. Asimismo: cf. SEELMANN, Kurt. Selbstherrschaft, Herrschaftüber die Dinge und individuelle Rechte in der Spanischen Spätscholastik, en KAUFMANN, Mathias; SCHNEPF, Robert (Ed.). Politische Metaphysik. Die Entstehung moderner Rechtskonzeptionen in der Spanischen Scholastik. Frankfurt: Peter Lang, 2007, pp. 43-57. E igualmente: cf. GUZMÁN BRITO, Alejandro. El derecho como facultad en la Neoescolástica española del siglo XVI. Madrid: Iustel, 2009, p. 25 ss.
} 
acomodar el primero a la ley evangélica, y al filósofo confrontar el segundo con los principios de la filosofía ${ }^{4}$.

Lo anterior no significa que los teólogos deban dedicarse a la "ciencia jurídica”. La ley y el derecho tienen un doble fin: la felicidad natural de la comunidad humana, como fin inmediato, y la bienaventuranza eterna, como fin mediato5. Su estudio, por consiguiente, "[...] corresponde por igual a juristas y teólogos, si bien bajo aspectos diferentes: a los juristas, en cuanto dicen orden al bien común de la república; y a los teólogos, en cuanto conducen a la persona, dentro de la comunidad, a la felicidad eterna"6.

Esto explica que los teólogos de la Escolástica española, como Domingo de Soto, Melchor Cano, Juan de la Peña y el mismo Luis de León, fueran también eminentes juristas ${ }^{7}$, una suerte de pensadores "ambidextros", que manejaban con gran pericia los saberes jurídicos a la vez que teológicos ${ }^{8}$. En el caso de fray Luis, además de su formación en la facultad salmantina de Cánones, al menos por un semestre académico, su conocimiento del derecho

\footnotetext{
${ }^{4}$ SOTO, Domingo de. De Iustitia et Iure, proemio. Tal había sido la enseñanza de Francisco de Vitoria. En su opinión, el oficio del teólogo es tan vasto, que "[...] ningún argumento, ninguna disputa, ninguna materia, parecen ajenos a su profesión". VITORIA, Francisco de. De Potestate Civili, proemio. También Suárez defiende la autoridad de los teólogos para el estudio de los asuntos jurídicos: si se pretende que el derecho sea algo más que un simple conglomerado de reglas de organización, "[...] si se desea verle incluido en la verdadera ciencia, es necesario unirlo, subalternarlo, a la filosofía". SUÁREZ, Francisco. De Legibus, proemio.

${ }^{5}$ Cf. FOLGADO, Avelino. Los tratados De Legibus y De Iustitia et Iure en los autores espańoles del siglo XVI y primera mitad del siglo XVII, en La ciudad de Dios, vol. 172 n. 3, p. 292, 1959.
}

6 MEDINA, Bartolomé de. Expositio in I-II, q. 90, artículo introductorio.

${ }^{7}$ Como apunta Brian Tierney, tanto León como el resto de los pensadores neoescolásticos estaban fuertemente influenciados por las compilaciones jurídicas del derecho romano y medieval, que habían sido asimiladas por las fuentes teológicas de las que se valían para sus investigaciones. Cf. TIERNEY, Brian. L'idea dei diritti naturali. Diritti naturali, legge naturale e diritto canonico 1150-1625. Bolonia: Il Mulino, 2002, p. 373. A iguales conclusiones ha llegado el profesor Miguel-Anxo Pena: cf. PENA, Miguel-Anxo. Derecho natural y ley natural en las Indias. La propuesta de Vitoria, en Laurentianum, n. 49, p. 121-138, 2008.

${ }^{8}$ Cf. GARCÍA Y GARCÍA, Antonio. El mundo del derecho en el Siglo de Oro de Salamanca, en VV.AA. El siglo de Fr. Luis de León. Salamanca y el Renacimiento. Salamanca: Ministerio de Cultura, 1991, p. 69 ss. Ahora bien, el oficio de teólogo-jurista no fue del todo aceptado entre los pensadores de la Escolástica renacentista. Alberico Gentili, por ejemplo, exhortaba a los teólogos a no salir de los límites de su ciencia en búsqueda de problemas que estaban fuera de su competencia, como los asuntos jurídicos. Por eso exclamaba: jsilete theologi in munere alieno!. Cf. GENTILI, Alberico. De Iure Belli, 1, c. 12 . 
civil y eclesiástico lo obtuvo de sus estudios como religioso de la orden de los agustinos de la ciudad de Tormes?.

Pese a que no asistió a sus lecciones, entró en contacto con Francisco de Vitoria por medio de uno de sus maestros, Diego de Covarrubias ${ }^{10}$. Asimismo, conoció los comentarios de Domingo de Soto a la Prima Secundae y Secunda Secundae de la Summa de santo Tomás ${ }^{11}$. Consta, igualmente, que él mismo explicó su teoría de las leyes en la universidad salmantina, mientras regentaba la colegiatura de Durando, en el curso de 1570-1571 ${ }^{12}$.

Aunque no haya ocupado cátedras de Decreto o Decretales, como sí lo hicieron Azpilcueta y Covarrubias, y todavía menos de Instituciones o Digesto, a lo Nebrija o Vázquez de Menchaca, sin embargo, sí se puede destacar su profundo conocimiento del mos italicus ${ }^{13}$. Tal era su autoridad en materias jurídicas y de gobierno, que el rey Felipe II lo consultaba en todos los casos graves enviándole correos extraordinarios a Salamanca ${ }^{14}$. No son gratuitas, de esta

\footnotetext{
${ }^{9}$ Cf. RODRÍGUEZ, José. Fray Luis de León, canonista (manuscrito inédito De Symonia), en Anuario jurídico y económico escurialense, n. 28, p. 156, 1995.

${ }^{10}$ Cf. PEREÑA, Luciano. Diego de Covarrubias, maestro de derecho internacional. Madrid: Asociación Francisco de Vitoria, 1957, p. 34-35.

${ }^{11}$ Cf. HERRERA, Rosa María. La etimología de lex en el tratado De Legibus de fray Luis de León, en La ciudad de Dios, n. 204, p. 701-711, 1991. En cuanto al estudio de los asuntos jurídicos por parte de los autores de la Neoescolástica, es importante tener en cuenta lo siguiente: "[...] todas las partes de la Suma fueron estudiadas y todas dieron ocasión a nuestros teólogos para escribir grandes tratados de alta especulación teológica y metafísica [...] Pero primó el matiz práctico connatural al genio español de estirpe senequista. Por eso la II-II y las qq. 90-108 de la I-II, donde el Santo expone la materia de la ley fue la materia predilecta de sus lecciones. Su estudio dio lugar a la ciencia moral, política y jurídica, que nuestros teólogos remansaron a los gruesos infolios De Iustitia et Iure y De Legibus". FOLGADO, Los tratados De Legibus y De Iustitia et Iure en los autores espańoles del siglo XVI y primera mitad del siglo XVII, cit., p. 276.
}

${ }^{12}$ Por este motivo, es claro que "[...] fray Luis no era un intruso en esa materia, ya que, al llegar a Salamanca, empezó estudiando derecho canónico. Ni por temperamento ni por afición era el clásico hombre de leyes, mas no puede decirse que la problemática jurídica le fuera extrańa. Por tanto, pudo tomar parte en los debates que sobre esas materias empezaron a cundir en las aulas en las que ejercía su magisterio". ÁLVAREZ TURIENZO, Saturnino. Ley y vida en el pensamiento moral de fray Luis de León, en Religión y Cultura, vol. 22 n. 93-94, p. 509, 1976.

${ }^{13}$ Cf. GARCÍA Y GARCÍA, El mundo del derecho en el Siglo de Oro de Salamanca, cit., p. 81. En este sentido, en sus doctrinas políticas, León “[...] se mueve en el área del derecho común romanocanónico medieval, es decir, el derecho de los dos Corpus juris, civil y canónico, que conforman el derecho justinianeo y Decreto de Graciano y Decretales". RODRÍGUEZ, Fray Luis de León, canonista (manuscrito inédito De Symonia), cit., p. 156.

${ }^{14} \mathrm{Cf}$. PACHECO, Francisco. Libro de descripción de verdaderos retratos de ilustres y memorables varones (1599). Sevilla: Disputación Provincial, 1985, p. 12. 
forma, las afirmaciones de Francisco Pacheco cuando llama a fray Luis judiciario eminente en uno y otro derecho ${ }^{15}$.

El pensamiento jurídico de León, localizado principalmente en su De Legibus, aunque esparcido también en otras de sus obras latinas y castellanas ${ }^{16}$, se inscribe en un

[...] modelo jurídico originado en Dios, destinado al hombre y proyectado al mundo: frente al iusnaturalismo racionalista protestante, al empirismo exegético francés, al historicismo casuístico inglés, al sociologismo ecléctico norteamericano o al racionalismo dogmático alemán, el iusnaturalismo católico español, en el que se inserta la doctrina iusfilosófica de fray Luis, se centra como ningún otro en el hombre, valorando en toda su dimensión la naturaleza humana modelada por el Creador y asumiendo así una concepción integral de la condición humana ${ }^{17}$.

Además de la naturaleza de las normas y de la vinculación entre voluntad divina y ley humana, fray Luis se ha interesado por otras categorías jurídicas y políticas, por ejemplo: el problema de la autoridad ${ }^{18}$, la legitimidad de la guerra de conquista ${ }^{19}$, la naturaleza del bien común, la noción de castigo penal, entre otros. En sus explicaciones sobre éstos y otros temas de la filosofía de la justicia, lo que busca nuestro autor es hacer frente a los movimientos reformistas del siglo XVI, que han negado que la autoridad de la Iglesia tenga la potestad suficiente como para dictar normas fuera de las preceptuadas por el derecho divino o natural.

${ }^{15} \mathrm{Cf}$. PACHECO, Libro de descripción de verdaderos retratos de ilustres y memorables varones (1599), cit., p. 11-12. Según observa Castillo, existen algunas razones de por qué las ideas de fray Luis tienen un carácter jurídico más acentuado que las de otros autores de su tiempo. Entre ellas podemos señalar las siguientes: la tradición jurídica familiar, su proceso ante la Inquisición, los negocios jurídicos que por encargo de sus superiores hubo de resolver y su probada competencia como jurista. Cf. CASTILLO, Juan. El pensamiento jurídico-politico de fray Luis de León en el tratado De Legibus. Burgos: Universidad de Burgos, tesis de doctorado, 1998, p. 20.

${ }^{16}$ Cf. THOMPSON, Colin P. The lost works of Luis de León (1) De Simonia, en Bulletin of Hispanic Studies, vol. 57 n. 2, p. 95-102, 1980.

${ }^{17}$ VÁZQUEZ, Juan José. El pensamiento jurídico de fray Luis de León, en Nueva Etapa, n. 57 p. 53, 1991. ${ }^{18}$ Para una revisión de la interpretación leonina de la autoridad: cf. GIRÓN-NEGRÓN, Luis. Your Dove-Eyes among Your Hair locks: Language and Authority in Fray Luis de León's Respuesta que Desde su Prisión da a sus Émulos, en Renaissance Quarterly, vol. 54 n. 4, p. 1197-1250, 2001.

${ }^{19}$ Para una revisión de la posición de León sobre la guerra de conquista: cf. CONTRERAS, Sebastián. La guerra de conquista en los escritos de fray Luis de León, en Taller de Letras, número especial 3, p. 57-68, 2013. 
Esto es un error y una herejía manifiesta, escribe fray Luis ${ }^{20}$. Es de la esencia de la tarea de gobierno poder disponer sobre aquellas materias indiferentes ante la lex naturae ${ }^{21}$, lo que se prueba por las palabras de Aristóteles: lo justo positivo es aquello que antes de la disposición de la autoridad, esto es, antes de dar la ley, es indiferente, se puede hacer y dejar de hacer" ${ }^{22}$, pero que "[...] una vez establecida la ley, deja de ser indiferente; como cuando se establece que el rescate cueste una mina, o que haya que sacrificar una cabra y no dos ovejas" ${ }^{23}$. Asi, enseña León que mediante las leyes humanas se han establecido muchas cosas que, antes de promulgarse esas leyes, eran indiferentes, y en consecuencia no estaban ni prohibidas ni prescritas por el derecho natural o divino ${ }^{24}$.

De lo anterior se sigue el firme rechazo que hace fray Luis de las doctrinas de Lutero ${ }^{25}$. El pensador alemán ha querido liberar al cristianismo de la juridificación eclesiástica del Medievo para recuperar su dimensión espiritual ${ }^{6}$. Éste es el motivo por el que el reformador propone un uso de la ley humana meramente preventivo (o negativo) ${ }^{27}$, ya que, según explica, toda ley sirve de ocasión para pecar ${ }^{28}$. Sólo la gracia salva ${ }^{29}$.

Sentado lo anterior, un punto en el que León critica con fuerza la enseñanza protestante es el que dice relación con la obligatoriedad de la ley

${ }^{20}$ Cf. BARRIENTOS, José. Fray Luis de León. Epistolario: cartas, licencias, poderes, dictámenes. Madrid: Agustiniana, 2001, doc. 56, p. 173. De la misma manera: cf. LEÓN, Luis de. De Lege, ed. Barrientos, q. 96, a. 4.

${ }^{21}$ Cf. LEÓN, Luis de. De Lege, ed. Barrientos, q. 98, a. 1.

${ }^{22}$ Cf. LEÓN, Luis de. De Lege, ed. Pereña, q. 7, a. 3.

${ }^{23}$ ARISTÓTELES, Ethica Nicomachea, 1134b 18-20.

${ }^{24}$ Cf. LEÓN, Luis de. De Lege, ed. Pereña, q. 7, a. 3.

${ }^{25}$ La reacción de León es, posiblemente, una de las más firmes oposiciones a las doctrinas de Lutero y los alumbrados: cf. RODRIGUES, Manuel Augusto. Ecos da exegese judaica medieval nas obras bíblicas de Fr. Luis de León, Fr. Luís de Sotomaior e Fr. Heitor Pinto, en SOTO, José María (Coord.). Pensamiento medieval hispano. Homenaje a Horacio Santiago-Otero. Madrid: CSIC, 1998, p. 1387.

${ }^{26}$ Cf. GONZÁLEZ, Adolfo. Reforma luterana y tradición católica. Salamanca: Publicaciones Universidad Pontificia, 1987, p. 60.

${ }^{27}$ Para una revisión del papel que Lutero le entrega a las leyes humanas: cf. ARAND, Charles; KOLB, Robert; NESTINGEN, James. The Lutheran Confessions. History and Theology of The Book of Concord. Mineápolis: Fortress Press, 2012, p. 198-199. Esta función preventiva o negativa de la ley se puede advertir en el siguiente pasaje de la obra luterana: la ley no es contraria a la promesa de la salvación, "[...] puesto que ha sido dada para causar la muerte y para incrementar el pecado, esto es, para que por medio de la ley el hombre vea cuán imperiosamente necesaria le es la gracia”. LUTERO, Martín. In Galatas, III, 21.

${ }^{28}$ Cf LUTERO, Martín. In Romanos, II, 12.

${ }^{29}$ Cf. LUTERO, Martín. In Romanos, III, 27. 
humana. Lutero, que se habría nutrido de las teorías gersonianas sobre la naturaleza de la ley ${ }^{30}$, afirma que las normas del derecho humano no obligan en el fuero de la conciencia. Los poderes humanos no pueden obligar en el fuero interno, porque el derecho regula solamente las acciones exteriores: únicamente Dios puede juzgar los corazones de los hombres ${ }^{31}$.

El pensamiento jurídico de León es resueltamente contrario a estas afirmaciones. Existe un deber general de obediencia del derecho que surge de la necesidad de cumplir con lo establecido por el gobernante en razón del bien social. Empleando el vocabulario de los teóricos de la ciencia jurídica contemporánea, algo es obligatorio cuando se le presenta al sujeto como una buena razón para la acción ${ }^{32}$. Esto significa que la obligación de las leyes humanas no se queda en el ámbito de las imposiciones externas sobre la conciencia del ciudadano, sino que traspasa al fuero interno del individuo a la manera de un cierto principio del obrar, que el sujeto asume (o no) libre y conscientemente.

Tal capacidad para vincular en el foro de la conciencia, ha hecho que fray Luis sea enfático en declarar que obrar en contra de la ley humana implica un mal de culpa ${ }^{33}$. La razón es la siguiente: si la ley es justa constituye una regla de la razón. Ahora bien, "[...] traspasar los límites de la razón es un extravío y, por tanto, una culpa, grave o leve, según sea la materia y la intención"34. Además, y puesto que todo poder procede de $\operatorname{Dios}^{35}$, el no cumplimiento de las órdenes de la autoridad supone, a la vez, un atentado al orden de la voluntad divina ${ }^{36}$.

Esta capacidad para dar normas que obligan en el fuero interno es un aspecto esencial de la tarea de gobierno. La comunidad política exige la

\footnotetext{
${ }^{30}$ Cf. PRODI, Paolo. Una historia de la justicia. De la pluralidad de fueros al dualismo moderno entre conciencia y derecho. Buenos Aires: Katz, 2008, p. 190-191.

${ }^{31}$ Cf. GERSON, Juan de. De Vita Spirituali Animae, lect. 4, cor. 5.

${ }^{32}$ Cf. RAZ, Joseph. Razón práctica y normas. Madrid: CEPC, 1991, p. 114.

${ }^{33}$ Cf. LEÓN, Luis de. In Epistolam ad Romanos Expositio, XIII, fol. 436r. La desobediencia de las leyes humanas implica un mal de culpa, porque al desobedecer a la autoridad se está desobedeciendo a Dios, y no sujetarse a sus leyes es una forma de engreimiento, dice fray Luis. Cf. LEÓN, Luis de. In Job Commentaria, XXXI, 17.

${ }^{34}$ CRUZ, Juan. Fragilidad humana y ley natural. Cuestiones disputadas en el Siglo de oro, Pamplona, Eunsa, 2009, p. 229.

${ }^{35}$ Cf. LEÓN, Luis de. In Epistolam ad Romanos Expositio, XIII, fol. 436r.

${ }^{36}$ Cf. LEÓN, Luis de. De Gratia et Iustificatione, q. 13, a. 2, fol. 109r.
} 
existencia de un principio de orden y regulación de la vida social. No hay sociedad que pueda conseguir el bien público sin una autoridad que regule la conducta de sus ciudadanos por medio de la actividad legislativa. La ley es, por tanto, una exigencia de justicia, y la práctica de la justicia es una exigencia del buen gobierno ${ }^{37}$.

\section{El DERECho o LeY NATURAL}

Recientemente se ha escrito que la genuina doctrina de León acerca del derecho natural debe ser buscada en sus comentarios al Libro de Job ${ }^{38}$. Si bien en esta obra es posible encontrar algunas de las intuiciones jurídicas de nuestro autor $^{39}$, no nos parece acertada esta afirmación, máxime en consideración de que el corpus leoninum cuenta con una significativa exposición del Tratado de la ley ${ }^{40}$.

El concepto de ley natural es la clave de todos los postulados teológicojurídicos del pensamiento luisiano, ya que es la parte más accesible a nuestro conocimiento de la ley eterna ${ }^{41}$. Se trata del ordenamiento de justicia que Dios ha establecido como conveniente para la consecución del fin natural de las cosas ${ }^{42}$. En cuanto a la vida humana,

[...] hace que el hombre discierna el bien y la justicia de la maldad y la injusticia; y no sólo el cristiano, sino todo aquel que no ha corrompido la

${ }^{37}$ Cf. LEÓN, Luis de. In Job Commentaria, XXXIV, 17.

${ }^{38}$ Cf. DÍAZ, José Manuel. La ley natural en fray Luis de León: un código escrito en clave crística, en MURILLO, Ildefonso (Coord.). El Barroco iberoamericano y la modernidad. Actas del VI Simposio internacional del Instituto de Pensamiento Iberoamericano (Salamanca, 12-14 de septiembre de 2012). Salamanca: Publicaciones Universidad Pontificia, 2013, p. 233-238.

${ }^{39}$ Cf. CAMINERO, Juventino. Fray Luis de León comentarista, o la razón filosófica, en VILANOVA, Antonio (Coord.). Actas del X Congreso de la Asociación Internacional de Hispanistas. Barcelona: PPU, 1992, p. 377.

${ }^{40}$ Según observa Barrientos, de los comentarios frayluisianos al De Legibus se conservan actualmente dos manuscritos: uno en Coímbra, ms. 1843, fols. 113-223, que contiene la lectura completa; y otro en la Biblioteca de la Real Academia de la Historia de Madrid, que contiene un fragmento sobre la Ley Antigua, ms. 9/2081, fols. 176-187v. Luciano Pereńa editó en 1963 de forma incompleta el manuscrito conimbricense, ya que dejó fuera de su edición todo lo referido a la ley positiva divina. Recién desde 2005 contamos con una edición crítica de todo el códice 1843. Cf. BARRIENTOS, José. Los tratados De Legibus y De Iustitia et Iure en la Escuela de Salamanca de los siglos XVI y XVII, en Salamanca. Revista de Estudios, n. 47, p. 380, 2001.

${ }^{41}$ Cf. CASTILLO, El pensamiento jurídico-politico de fray Luis de León en el tratado De Legibus, cit., p. 304.

${ }^{42}$ Cf. LEÓN, Luis de. In Genesim Expositio, fol. 35r. 
recta naturaleza con su conducta depravada, y tanto más cuanto cada uno es mejor y más inteligente ${ }^{43}$.

Su fin inmediato es el bien proporcionado a la naturaleza humana, porque Dios, que es el autor de estas leyes intenta aquel bien proporcionado a la naturaleza ${ }^{44}$. Como ordenamiento de justicia, se compone de una serie de proposiciones y principios prácticos evidentes o deducidos de modo evidente de principios per se notae omnibus ${ }^{45}$. Luego, no sólo los llamados prima principia pertenecen a lo justo natural. También son de derecho natural las consecuencias deducidas inmediatamente de esos primeros principios ${ }^{46}$. Esto porque participan de la racionalidad, de la verdad y de la justicia de los principios generales del orden práctico ${ }^{47}$.

Este conjunto de proposiciones morales universales tienen razón de ley, es decir, en su naturaleza mandan hacer lo intrínseca y manifiestamente bueno y rechazan lo intrínseca y manifiestamente malo ${ }^{48}$. En concreto, escribe fray Luis:

[...] la ley natural prohíbe todas y cada una de las cosas que son nocivas por su naturaleza; preceptúa, en cambio, lo que es justo por su naturaleza, no todo ciertamente, sino únicamente lo que es conveniente y necesario para su fin natural ${ }^{49}$.

Esos preceptos reflejan el orden de la naturaleza, que, a su vez, es una imagen del orden universal ${ }^{50}$. Asimismo, le imponen direccionalidad a nuestras acciones. Es decir, puesto que todo actuar se encuentra necesariamente dirigido

${ }^{43}$ GINÉS DE SEPÚlVEDA, Juan. Democrates Alter, p. 12.

${ }^{44}$ Cf. LEÓN, Luis de. De Lege, ed. Barrientos, q. 90, a. 2.

${ }^{45}$ Cf. LEÓN, Luis de. De Lege, ed. Barrientos, q. 94, a. 2.

${ }^{46}$ Cf. LEÓN, Luis de. De Lege, ed. Pereña, q. 5. a. 1.

${ }^{47}$ Cf. LEÓN, Luis de. De Lege, ed. Pereña, q. 5. a. 1.

${ }^{48}$ Cf. RAMÍREZ, Santiago. El derecho de gentes. Examen crítico de la filosofía del derecho de gentes desde Aristóteles hasta Francisco Suárez. Buenos Aires-Madrid: Studium, 1955, p. 61.

${ }^{49}$ LEÓN, Luis de. De Lege, ed. Barrientos, q. 92, a. 2. Prosigue León: la ley natural también permite ciertas cosas, "[...] en primer lugar, porque permite lo que es indiferente según su naturaleza; en segundo, y se dice con mayor propiedad permitirlo la ley natural, porque las leyes llamadas humanas y los legisladores deben a veces permitir algo malo para que no se deriven de la prohibición de ello mayores perjuicios".

${ }^{50}$ Cf. PAGDEN, Anthony. The Preservation of Order: The School of Salamanca and the Ius Nature, en HODCROFT, Frederick William (Ed.). Medieval and Renaissance Studies on Spain and Portugal in Honour of P. E. Russell. Oxford: The Society for the Study of Medieval Languages and Literature, 1981, p. $155-166$. 
a un fin o fines que son, al nivel de esos principios primeros, los objetos de las inclinaciones naturales, tales preceptos marcan la dirección a la que debe apuntar el actuar humano ${ }^{51}$ : "se debe hacer el bien y evitar el mal", "no se debe hacer a los demás lo que no queremos que ellos hagan a nosotros", "se debe obrar conforme a la recta razón”.

Pese a que existe una multiplicidad de preceptos, el derecho o ley natural es uno y el mismo, escribe León ${ }^{52}$. Para explicar la dependencia que tienen todos los derechos naturales del primer principio práctico, fray Luis utiliza un argumento que no había sido considerado por santo Tomás. En concreto, enseña: así como en los movimientos es necesario suponer un principio único que mueve y es inmóvil,

[...] en virtud del cual se mueve todo lo demás, así también en la misma medida en el discurrir de la razón, que consiste en un cierto movimiento, es necesario suponer un único principio, conocido por sí mismo, y con cuya potencia se puedan conocer las demás cosas ${ }^{53}$.

Este principio es en la razón especulativa aquel del que es imposible afirmar y negar al mismo tiempo respecto de una misma $\operatorname{cosa}^{54}$; y en la razón práctica, " [...] el primer principio gracias al cual todo se aclara, es el que sigue: hay que tratar de alcanzar el bien, ha de evitarse el mal, como dice Aristóteles en el libro primero de la Ética" 55 .

Es curioso, finalmente, que fray Luis se remita, al momento de enunciar el primer principio práctico, al texto de Ethica Nicomachea. Es cierto que santo Tomás expresa en I-II, 94, 2 que el principio captado por el hábito de la sindéresis se encuentra relacionado con aquello que enseña Aristóteles sobre el bien: que se trata de lo que todas las cosas apetecen. Pero es manifiesto que lo que está en la mente del filósofo griego no es una formulación imperativa del principio primero de la vida moral. Se trata, más bien, de una constatación de lo que, metafísicamente, sucede en el orden natural ${ }^{56}$.

${ }^{51}$ Cf. MOLINA, Enrique. La moral entre la convicción y la utilidad. La evolución de la moral desde la manualistica al proporcionalismo y al pensamiento de Grisez-Finnis. Pamplona: Eunate, 1996, p. 123 ss.

${ }^{52}$ Cf. LEÓN, Luis de. De Lege, ed. Barrientos, q. 94, a. 2.

${ }^{53}$ LEÓN, Luis de. De Lege, ed. Barrientos, q. 94, a. 2.

${ }^{54}$ Cf. LEÓN, Luis de. De Lege, ed. Barrientos, q. 94, a. 2.

${ }^{55}$ LEÓN, Luis de. De Lege, ed. Barrientos, q. 94, a. 2.

${ }^{56}$ Es de notar que santo Tomás, en sus Comentarios a la Ética, no establece la vinculación propuesta por Luis de León entre la noción aristotélica del bien y el primer principio de la razón práctica. Cf. 


\section{LA LEY HUMANA, SU NECESIDAD}

La ley natural no es otra cosa que el conocimiento infundido por Dios en el hombre en virtud del cual éste se dirige de un modo conveniente en sus acciones $^{57}$. Se trata, en todo caso, de un conocimiento muy delimitado ${ }^{58}$, en el que se aprehenden unos pocos principios de justicia absolutos y generales, indemostrables y conocidos de todos ${ }^{59}$, que versan sobre lo intrínsecamente bueno y justo, y que son como el germen de todo conocimiento posterior ${ }^{60}$, pero que no agotan el ámbito de lo necesario para la vida humana ${ }^{61}$.

Esta limitada forma de conocimiento es insuficiente para dar respuesta a todos los problemas de coordinación que se deducen en la vida social ${ }^{62}$, porque lo justo natural no determina cuál es la decisión más adecuada para cada problema en particular ${ }^{63}$. Así se explica que la prudencia jurídica deba avanzar en el razonamiento práctico hacia reglas de la acción más particulares y que tomen en consideración las circunstancias variantes y los detalles que rodean cualquiera y cada uno de los actos morales ${ }^{64}$.

Esa actividad de la prudencia tiene un valor eminentemente constitutivo, en tanto que dispone como obligatorio un asunto no tratado, en principio, por las leyes naturales. Por esto enseña fray Luis que la ley humana no es una mera transcripción del derecho natural ${ }^{65}$. Y por esto se explica que los preceptos de la ley humana no tengan una conexión directa con el derecho por naturaleza, sino sólo en cuanto se trata de principios convenientes para el bienestar político.

En este sentido, cuando la ley humana ordena algo, por ejemplo el pago de un gravamen, no define la bondad moral de ese acto, pues no hace que

SANTO TOMÁS, In Ethicorum, lib. I, lect. 1, n. 2.

${ }^{57}$ Cf. SANTO TOMÁS, Summa Theologiae, Sup, q. 65, a. 1.

${ }^{58}$ Cf. SANTO TOMÁS, Contra Gentes, III, c. 54.

${ }^{59}$ Cf. SANTO TOMÁS, Summa Theologiae, I-II, q. 94, a. 6.

${ }^{6}$ Cf. SANTO TOMÁS, De Veritate, q. 16, a. 1.

${ }^{61}$ Cf. HERVADA, Javier. Esencia del matrimonio y consentimiento matrimonial, en su Escritos de derecho natural. Pamplona: Eunsa, 1986, p. 480.

${ }^{62}$ Cf. FINNIS, John. Natural Law. The Classical Tradition, en COLEMAN, Jules; SHAPIRO, Scott (Ed.). The Oxford Handbook of Jurisprudence and Philopsophy of Law. Oxford: Oxford University Press, 2002, p. 23.

${ }^{63}$ Cf. PEREIRA, Carolina. La autoridad del derecho. Un diálogo con John M. Finnis. Granada: Comares, 2008, p. 187.

${ }^{64}$ Cf. LEÓN, Luis de. De Nominibus Christi, p. 454.

${ }^{65}$ Cf. LEÓN, Luis de. De Lege, ed. Barrientos, q. 95, aa. 1-2. 
una cosa sea buena o esté de acuerdo con la razón natural, sino, únicamente, impone la obligación de que se haga, y de que se haga de tal o cual modo ${ }^{66}$.

Las normas del derecho humano, cuya justicia se deriva de los principios naturales ${ }^{67}$, no pueden ser contrarias a la razón natural ${ }^{68}$. Ahora bien, que se deriven de la ley natural no significa que estén constituidas por ella, o que sus contenidos sean establecidos por lo justo natural. Lo que significa, sostiene León, es que la ley humana pretende el mismo fin que la ley natural ${ }^{69}$, no obstante que se haga cargo de materias que de suyo no pertenecían a lo justo por naturaleza. Esto hace que aunque una ley positiva no sea propiamente constituida por la ley natural, ni su materia se derive de ésta, sí al menos, y sólo en algún grado, su fuerza obligatoria, por pretender el mismo fin y obligar a los ciudadanos, por razones distintas, a intentar alcanzarlo ${ }^{70}$.

Según expone León, las leyes positivas son necesarias para que el hombre sea bueno. La inclinación del hombre a la virtud, que es debida a la ley natural, no es suficiente para que los ciudadanos sean verdaderamente justos. Para esto se requiere disciplina, la que se consigue solamente, escribe, por medio de la ley humana ${ }^{71}$.

La necesidad de estas normas se exhibe, además, en el hecho de que, en ocasiones,

[...] las personas pueden tener motivos emocionales para actuar de forma contraria a la orientación integral dada por los bienes humanos (algunas veces por la persecución de bienes genuinamente humanos aunque parciales, a los que se encuentra profundamente vinculado o atado $)^{72}$.

${ }^{66}$ Cf. PEREÑA, Luciano. Luis de León. De Legibus o Tratado de las leyes (1571). Madrid: CSIC, 1963, p. LXI.

${ }^{67}$ Cf. LEÓN, Luis de. De Lege, ed. Barrientos, q. 95, a. 2.

${ }^{68}$ Cf. LEÓN, Luis de. De Gratia et Iustificatione, q. 13, a. 2, fol. 110r.

${ }^{69}$ Cf. LEÓN, Luis de. De Lege, ed. Pereña, q. 7, a. 3.

${ }^{70}$ Cf. CASTILLO, El pensamiento jurídico-político de fray Luis de León en el tratado De Legibus, cit., p. 402.

${ }^{71}$ Cf. LEÓN, Luis de. De Lege, ed. Barrientos, q. 95, a. 1.

${ }^{72}$ GEORGE, Robert P. Kelsen y Santo Tomás sobre la doctrina de la ley natural, en Persona y Derecho, n. 42 , p. $81,2000$. 
Esto no significa, sin embargo, que las emociones en sí mismas sean malas o que debieran ser eliminadas de algún modo ${ }^{73}$. Sólo quiere decir que, en estas situaciones, el esfuerzo individual por conseguir la perfección moral puede no ser suficiente, lo que justifica, como observa George, el establecimiento de la ley positiva y la competencia del Estado para establecer ese tipo de leyes ${ }^{74}$.

Igualmente, la conveniencia de las leyes humanas radica en la necesidad de regular y uniformar los comportamientos sociales ${ }^{75}$. El derecho natural por sí solo posee una incapacidad efectiva para garantizar la convivencia justa y pacífica entre los hombres. Luego, solamente las leyes humanas pueden conseguir la armonía y la unidad en las costumbres, así como la concordia y amistad entre los ciudadanos $^{76}$. La razón es ésta: para conseguir la armonía y la paz social no basta la buena intención de los ciudadanos "[...] sino la uniformidad o unidad en los comportamientos como efecto de la imperatividad de la ley" 77 .

León incluye un argumento más, que no se encuentra en los autores que lo precedieron. Propone que la ley humana es necesaria para facilitar la consecución del fin propio de la ley natural ${ }^{78}$. En alguna medida, la ley positiva es más completa que la ley natural, pues al disponer los medios para cumplir los preceptos naturales, considera, además de lo preceptuado por el orden de la razón, las distintas circunstancias en que se realizan los actos humanos.

De lo expuesto concluye León que no existe problema en que ciertas materias empiecen a ser justas por la pura voluntad de los hombres ${ }^{79}$, en la medida que las leyes positivas regulan los detalles de la acción no cubiertos por el derecho natural. Así, la ley positiva determina y concreta en las personas y hechos particulares lo que en el derecho natural es sólo un principio general ${ }^{80}$. De ahí que lo que se manda en la ley humana no es por esencia bueno y justo sino sólo

\footnotetext{
${ }^{73}$ Cf. GEORGE, Kelsen y Santo Tomás sobre la doctrina de la ley natural, cit., p. 81.

${ }^{74} \mathrm{Cf}$. GEORGE, Kelsen y Santo Tomás sobre la doctrina de la ley natural, cit., p. 81.

${ }^{75}$ Cf. LEÓN, Luis de. De Lege, ed. Barrientos, q. 95, a. 2.

${ }^{76}$ Cf. CASTILLO, El pensamiento jurídico-político de fray Luis de León en el tratado De Legibus, cit., p. 386.

${ }^{77}$ CASTILLO, El pensamiento jurídico-politico de fray Luis de León en el tratado De Legibus, cit., p. 386.

${ }^{78}$ LEÓN, Luis de. De Lege, ed. Barrientos, q. 95, a. 1.

${ }^{79}$ Cf. LEÓN, Luis de. De Lege, ed. Pereńa, q. 5, a. 3.

${ }^{80}$ Cf. CASTILLO, Juan. El mundo jurídico en fray Luis de León. Burgos: Publicaciones Universidad de Burgos, 2000, p. 191.
} 
porque ha sido mandado ${ }^{81}$, a diferencia de lo que está bajo la ley natural, que es siempre bueno y necesario para conseguir la perfección humana.

Se confirma con esto la idea de los doctores escolásticos, según la cual

[...] unas cosas son necesarias por su naturaleza, y esas son las cosas justas naturales, y por ello se prescriben por ley. Otras, en cambio, son necesarias para afianzar la virtud por disposición de la ley, y esas son las cosas justas legales, puesto que, excluida la ley, no serían necesarias, por más que sí útiles y cumplideras ${ }^{82}$.

En definitiva, supuesto que la ley humana puede crear contenidos de justicia originariamente inexistentes por derecho de naturaleza, se sigue que las leyes positivas, al prescribir algo, no sitúan la rectitud de lo mandado en el objeto del acto, sino sólo instalan la obligación de que eso se haga ${ }^{83}$. Y así, escribe fray Luis, pueden estarse al mismo tiempo estas dos cosas:

[...] que todo acto preceptuado por la ley humana sea conforme a la razón por su propia naturaleza, y también que ese acto no pertenezca a la ley de la naturaleza, sino a la ley humana, puesto que la obligación de hacerlo nació de la ley humana solamente. En efecto, no estamos obligados a hacer todo lo que es concorde con la razón, y, sin embargo, estamos obligados a hacerlo sólo cuando lo preceptúa la ley humana ${ }^{84}$.

\section{EL DERECHO DE GENTES}

Comienza fray Luis su exposición poniendo de relieve la gran confusión que existía en torno al problema del ius gentium, no sólo por parte de los juristas latinos, que unas veces lo confundían con el derecho natural y en otras ocasiones lo distinguían de él ${ }^{85}$, sino también por parte de santo Tomás, que, aunque divide el derecho positivo en civil y de gentes ${ }^{86}$, parece indicar que

\footnotetext{
${ }^{81}$ Cf. LEÓN, Luis de. De Lege, ed. Pereña, q. 5, a. 3.

${ }^{82}$ LEÓN, Luis de. De Lege, ed. Pereña, q. 6, a. 2.

${ }^{83}$ Cf. LEÓN, Luis de. De Lege, ed. Pereña, q. 6, a. 2.

${ }^{84}$ LEÓN, Luis de. De Lege, ed. Pereña, q. 6, a. 2.

${ }^{85}$ Cf. BARRIENTOS, El tratado De Legibus de fray Luis de León, cit., p. 153.

${ }^{86}$ Cf. SANTO TOMÁS, Summa Theologiae, I-II, q. 95, a. 4.
} 
las normas del ius gentium forman parte del derecho por naturaleza, al menos según lo que expresa en sus Comentarios a la Ética de Aristóteles ${ }^{87}$.

Además, León se enfrenta a la confusión de Domingo de Soto ${ }^{88}$, su maestro ${ }^{89}$, que dice que los primeros principios prácticos que el hombre conoce sin discurso, porque están impresos en nuestra inteligencia, pertenecen al derecho natural; pero que las conclusiones de estos principios pertenecen al derecho de gentes ${ }^{90}$. Según observa nuestro autor, esa doctrina es errónea, porque de ella se seguiría que los preceptos del Decálogo, en cuanto pertenecientes al derecho de gentes, podrían ser abrogados, lo cual es un absurdo $0^{91}$. Planteadas estas consideraciones, sostiene el agustino:

[...] lo que se deduce de los principios de la naturaleza con necesaria consecuencia tiene conexión necesaria con la rectitud natural, de tal modo que sin ello no puede tener consistencia la rectitud natural, por tanto son de derecho natural tan verdadera y propiamente como los propios principios; es evidente la conclusión, porque quien ordena algo, con ello mismo ordena todos los medios necesarios para conseguirlo ${ }^{92}$.

\section{Dado lo anterior, hay que señalar que de los principios del derecho natural}

[...] pueden deducirse doblemente algunas cosas: de una manera, absolutamente, según la necesidad, lo que vale decir que algunas son necesarias para la rectitud natural, considerando la naturaleza y condición humana de modo absoluto. En cambio, otras se siguen de los principios de derecho natural tan sólo de modo necesario, pero no de modo absoluto, sino luego de realizarse alguna suposición, lo que equivale a decir que algunas son necesarias para adquirir la virtud y rectitud naturales; no,

\footnotetext{
${ }^{87}$ SANTO TOMÁS, In Ethicorum, V, lect. 12, n. 1019. La idea es la siguiente: las conclusiones directas e inmediatas obtenidas desde los principios primarios, que conforman el derecho de gentes, son también un derecho natural, en el sentido de que también esas normas dicen relación con las conductas o acciones que convienen o no al hombre por su condición de tal. Y así, observa santo Tomás "[...] que el derecho de gentes es en cierto modo natural al hombre como animal racional, porque se deriva de la ley natural a manera de una conclusión no muy alejada de los principios". SANTO TOMÁS, Summa Theologiae, I-II, q. 95, a. 4.

${ }^{88}$ Cf. LEÓN, Luis de. De Lege, ed. Barrientos, q. 95, a. 4.

${ }^{89}$ Cf. LEÓN, Luis de. Luysii Legionensis Opera, V, p. 110, donde afirma: "[...] quam sententiams equutis unt magistri nostri Soto et Cano".

${ }^{90}$ Cf. SOTO, Domingo de. De Iustitia et Iure, I, q. 5, a. 4.

${ }^{91}$ Cf. LEÓN, Luis de. De Lege, ed. Barrientos, q. 95, a. 4.

${ }^{92}$ Cf. LEÓN, Luis de. De Lege, ed. Barrientos, q. 95, a. 4.
} 
ciertamente, de modo absoluto, sino una vez supuestos esa condición y estado del hombre ${ }^{93}$.

La conclusión a la que llega nuestro autor es la que sigue: lo que se obtiene de los principios de la naturaleza mediante necesaria consecuencia, considerada la naturaleza del hombre no de modo absoluto, sino previa alguna suposición, pertenece al derecho de gentes.

Pese a que se trata de un derecho intermedio, ubicado entre el derecho natural primario y el derecho positivo estricto, León considera que las normas del ius gentium pertenecen, stricto sensu, a lo justo positivo o legal. Esto se debe, sobre todo, a las diferencias sustantivas que existen entre una y otra clase de derecho: mientras que el derecho de gentes no manda nada que sea por sí mismo necesario para la rectitud de la conducta, ni prohíbe nada que sea esencial e intrínsecamente malo, el derecho natural ordena lo que por naturaleza es necesario para la perfección humana ${ }^{94}$. Además,

[...] el derecho de gentes es derogable y, de hecho, algunas de sus normas o preceptos ya han sido derogados, como es la propiedad privada en algunas comunidades cristianas y, asimismo, la servidumbre y esclavitud derivada de una victoria militar en guerra justa entre los cristianos $^{95}$.

Más allá de los esfuerzos de fray Luis por esclarecer este asunto, nos parece que él también incurre en una inconsistencia al referirse al derecho de gentes, similar, creemos, a la que presenta la teoría de Soto. Según enseńa el agustino, el derecho natural está constituido por los primeros principios prácticos y por las conclusiones que se deducen de ellos con una necesidad absoluta. También el derecho de gentes se forma por deducciones desde los principios naturales, pero no por deducciones necesarias, sino hipotéticas, considerando las distintas circunstancias en las que se desarrolla la vida moral y política.

En este sentido, León establece que la derivación por conclusión desde los preceptos naturales origina tanto reglas positivas como reglas naturales, y la única manera de distinguir unas deducciones de las otras es, al parecer, la

\footnotetext{
${ }^{93}$ Cf. LEÓN, Luis de. De Lege, ed. Barrientos, q. 95, a. 4.

${ }^{94}$ Cf. LEÓN, Luis de. De Lege, ed. Barrientos, q. 95, a. 4.

${ }^{95}$ BARRIENTOS, El tratado De Legibus de fray Luis de León, cit., p. 156.
} 
lejanía de las conclusiones. Esta idea entra en conflicto con la doctrina de los principios terciarios del derecho natural, en los que

[...] la fuerza de la consecuencia no es evidente sino muy probable, y así hace falta la doctrina de los grandes y sabios para que sean recibidas, como: no prestar para la usura, que se sigue de esto: no robarás, pero no tan claro que no pueda alguien dudar que por el beneficio mutuo puedan recibir pago ${ }^{96}$.

De la misma forma, las afirmaciones de fray Luis dejan sin explicación la derivación por determinación, porque la combinación de premisas iusnaturales con elementos de la realidad social tiene como resultado reglas del ius gentium y no preceptos del derecho positivo estricto, como había enseñado santo Tomás y los otros teólogos de la Escolástica del Medievo.

\section{CONSIDERACiONES FINALES}

Hay quienes han enfatizado que el fray Luis poeta y escritor ha perjudicado misteriosamente al teólogo y pensador que permanece inédito ${ }^{97}$. En alguna medida, ese juicio es acertado. A León se lo conoce más por su trabajo literario, o por su juicio inquisitorial, que por sus aportes a la teología y filosofía especulativa ${ }^{98}$. Así, en general, el conocimiento que disponemos de su obra filosófica es escaso, y todavía más escaso el que tenemos de su trabajo en filosofía del derecho.

Una parte importante de su obra pertenece, ciertamente, al campo de la teoría literaria, la mística y la hermenéutica, pero esto no significa que su obra teológico-jurídica sea de menor calado ${ }^{99}$. Por el contrario, las ideas de la tradición agustina del siglo XVI, de la cual fray Luis destaca como una pieza fundamental, contribuyeron decisivamente a la consolidación y desarrollo de

\footnotetext{
${ }^{96}$ SOTO, Domingo de. De Justitia, ms. ott. lat. 782, q. 57, a. 2.

${ }^{97}$ Cf. FOLGADO, Avelino. Cristocentrismo teológico en Fr. Luis de León. Madrid: El Escorial, 1968, p. 8.

${ }^{98}$ Cf. BELDA PLANS, Juan. Grandes personajes del Siglo de oro español. Madrid: Palabra, 2013, p. 243.

${ }^{99}$ Por este motivo, se ha escrito: "[...] no es éste, como es sabido, el aspecto más importante de la ingente obra del gran agustino, lo cual no quita para que haya sido injustamente olvidado. A nuestro modo de ver, el De Legibus de fray Luis debe ocupar un puesto relevante dentro de la literatura teológico-jurídica". CALONGE, Alfredo. Algunas observaciones a propósito del De Legibus de fray Luis, en ROSET, Jaime (Coord.). Estudios en homenaje al profesor Juan Iglesias. Madrid: Publicaciones Universidad Complutense, 1988, t. 1, p. 17.
} 
la llamada Escolástica española, no sólo en su vertiente estrictamente teológica, sino también en sus desarrollos jurídicos y morales.

Sin embargo, la filosofía de León no ha logrado estar presente, como debiera, en los trabajos de los principales estudiosos de la Neoescolástica del siglo XVI. Si bien hace algunos ańos las investigaciones sobre el pensamiento escolástico han vuelto a las aulas universitarias, casi enteramente han versado sobre pensadores como Francisco Suárez, Luis de Molina o Francisco de Vitoria. Por alguna razón, la agudeza intelectual del agustino ha quedado obscurecida por la figura y personalidad de estos autores.

CONTRERAS, Sebastián. Luis de León (1527-1591) and his Theory of Justice. Main Topics his Philosophy of Law. Trans/Form/Ação, Marília, v. 37, n. 1, p. 201-222, Jan./Abr., 2014.

ABSTRACT: The studies about Luis de León has focused mainly in his mystical, narrative and literary theory. In this paper, the author attempts to develop the principal aspects of his legal doctrine. Like other great theologians of The Salamanca School, also Leon has studied the issue of the nature of human law and its relationship with the natural law. This is precisely the thematic of the next article.

KEY WORDS: Luis de León. Natural law. Positive law. Salamanca School. Second Scholastic.

\section{Bibliografía}

\section{Obras de Luis DE LeÓN}

Tractatus de Religione. Tratado sobre la Religión. Edición bilingüe latín-español de José Rodríguez Díez. Madrid: San Lorenzo del Escorial, 2012.

Comentario sobre el génesis. Expositio in Genesim. Edición de Hipólito Navarro. Madrid: San Lorenzo del Escorial, 2009.

De Gratia et Iustificatione. Tratado sobre la Gracia y la Justificación. Edición bilingüe latínespañol de José Manuel Díaz. Madrid: San Lorenzo del Escorial, 2008.

Dios y su imagen en el hombre. Lecciones inéditas sobre el libro I de las Sentencias (1570). Edición de Santiago Orrego. Pamplona: Eunsa, 2008.

De Legibus. Tratado sobre la ley. Edición bilingüe latín-español de José Barrientos y Emiliano Fernández Vallina. Madrid: San Lorenzo del Escorial, 2005. 
Reportata Theologica. Edición de José Rodríguez. Madrid: San Lorenzo del Escorial, 1996. In Epistolam ad Romanos expositio. Edición de Gonzalo Díaz. Madrid: San Lorenzo del Escorial, 1993.

De legibus o Exposición del Libro de Job. Edición Javier San José Lera. Salamanca: Eusal, 1992. De los nombres de Cristo. Edición de Cristóbal Cuevas. Madrid: Cátedra, 19865.

La perfecta casada. Edición de Félix García. Madrid: BAC, 1967.

Tratado sobre la ley (1571). Madrid: CSIC, 1963. Edición bilingüe latín-espańol de Luciano Pereña.

Obras del M. Fr. Luis de León de la orden de San Agustín, reconocidas y cotejadas con varios manuscritos auténticos. Edición de Antolín Merino. Madrid: Imprenta de la viuda de Ibarra, 1804.

\section{Otras FUENTES}

ARISTÓTELES. Nicomachean Ethics. Edición de Christopher Rowe y Sarah Broadie. Oxford-Nueva York: Oxford University Press, 2002.

GENTILI, Alberico. De jure belli libri tres. Edición de James Brown Scott. Oxford: Clarendon Press, 1933.

GERSON, Juan de. Opera omnia. Edición de Louis Ellies du Pin. Hildesheim: Georg Olms, 1987.

GINÉS DE SEPÚLVEDA, Juan. Democrátes Segundo o De las justas causas de la guerra contra los indios. Edición de Ángel Losada. Madrid: Instituto Francisco de Vitoria, 1984.

LUTERO, Martín. Werke. Kritische Gesamtausgabe. Edición de Hermann Bohlaus Nachfolger. Weimar: Böhlau, 1883.

MEDINA, Bartolomé de. Expositio in Primam Secundae D. Thomae Aquinatis. Venecia: 1590.

SANTO TOMÁS. Opera omnia. Edición crítica dirigida por los Padres Predicadores. Roma: Commissio Leonina, 1989.

SOTO, Domingo de. De iustitia et iure libri decem. De la justicia y el derecho en diez libros. Edición bilingüe latín-español de Marcelino González. Madrid, Instituto de Estudios Políticos, 1967-1968.

SOTO, Domingo de. De Justitia, ms. ottob. lat. 781. Biblioteca Vaticana.

VITORIA, Francisco de. Relectio de Potestate Civili. Edición bilingüe latín-español de Jesús Cordero Pando. Madrid: CSIC, 2005. 


\section{LITERATURA SECUNDARIA}

ANDRÉS MARTÍN, Melquiades. La teología española del siglo XVI. Madrid, BAC, 1976. ÁLVAREZ TURIENZO, Saturnino. Fray Luis de León: formación humanística, humanismo platónico, platonismo teológico. In: VIŃAS ROMÁN, Teófilo (Coord.). Fray Luis de León. IV centenario (1591-1991). Congreso interdisciplinar. Madrid, 16-19 de octubre de 1991. Actas. Madrid: Ediciones Escurialenses, 1992.

ÁLVAREZ TURIENZO, Saturnino. Ley y vida en el pensamiento moral de fray Luis de León.Religión y Cultura, vol. 22 n. 93-94, 1976.

ARAND, Charles; KOLB, Charles; NESTINGEN, James. The Lutheran Confessions. History and Theology of The Book of Concord. Mineápolis: Fortress Press, 2012.

BARRIENTOS, José. El tratado De Legibus de fray Luis de León. In: Langella, Simona (Ed.). Atti del convegno Genesi, sviluppi e prospettive dei diritti umani in Europa e nel Mediterraneo (Genova, 26-28 ottobre 2004. Palazzo S. Giorgio). Nápoles: Guida, 2006.

BARRIENTOS, José. Fray Luis de León. Epistolario: cartas, licencias, poderes, dictámenes. Madrid: Agustiniana, 2001.

BARRIENTOS, José. Los tratados De Legibus y De Iustitia et Iure en la Escuela de Salamanca de los siglos XVI y XVII. Salamanca. Revista de Estudios, n. 47, 2001.

BARRIENTOS, José. Fray Luis de León y la Universidad de Salamanca. Madrid: Ediciones Escurialenses, 1996.

BARRIENTOS, José. Fray Luis de León. Escritos desde la cárcel. Autógrafos del primer proceso inquisitorial. Madrid: El Escorial, 1991.

BELDA PLANS, Juan. Grandes personajes del Siglo de oro español. Madrid: Palabra, 2013.

BELDA PLANS, Juan. La Escuela de Salamanca y el compromiso por la justicia. Communio, año 23, tercera época, 2001.

BELDA PLANS, Juan. La Escuela de Salamanca y la renovación de la teología en el siglo XVI. Madrid: BAC, 2000.

CALONGE, Alfredo. Algunas observaciones a propósito del De Legibus de fray Luis. In: ROSET, Jaime (Coord.). Estudios en homenaje al profesor Juan Iglesias. Madrid: Universidad Complutense, 1988.

CAMINERO, Juventino. Fray Luis de León comentarista, o la razón filosófica. In: VILANOVA, Antonio (Coord.). Actas del X Congreso de la Asociación Internacional de Hispanistas. Barcelona: PPU, 1992.

CAMPO DEL POZO, Fernando. Adaptación del derecho medieval y la poesía a un mundo moderno por fray Luis de León en el siglo XVI. In: LAZCANO, Rafael (Ed.). Fray Luis de León. Homenaje al profesor Jaime García Álvarez en su 65 aniversario. Madrid: Agustiniana, 1997. 
CAMPO DEL POZO, Fernando. Influencia del derecho medieval en fray Luis de León. SOTO, José María (Coord.). Pensamiento medieval hispano. Homenaje a Horacio SantiagoOtero. Madrid, CSIC, 1988.

CASTILLO, Juan. El mundo jurídico en fray Luis de León. Burgos: Publicaciones Universidad de Burgos, 2000.

CASTILLO, Juan. El pensamiento jurídico-politico de fray Luis de León en el Tratado De Legibus. 1998. Tesis (Doctorado) - Universidad de Burgos, Burgos, 1998.

CONTRERAS, Sebastián. La guerra de conquista en los escritos de fray Luis de León. Taller de Letras, n. 53, 2013.

CRUZ, Juan. Fragilidad humana y ley natural. Cuestiones disputadas en el Siglo de oro. Pamplona: Eunsa, 2009.

DÍAZ, José Manuel. La ley natural en fray Luis de León: un código escrito en clave crística. In: MURILLO, Ildefonso (Coord.). El Barroco iberoamericano y la modernidad. Actas del VI Simposio internacional del Instituto de Pensamiento Iberoamericano (Salamanca, 1214 de septiembre de 2012). Salamanca: Publicaciones Universidad Pontificia, 2013.

FERRARO, Domenico. Itinerari del volontarismo. Teologia e politica al tempo di Luis de León. Milán: Franco-Angeli, 1995.

FOLGADO, Avelino. Los tratados De Legibus y De Iustitia et Iure en los autores españoles del siglo XVI y primera mitad del siglo XVII. La ciudad de Dios, vol. 172 n. 3, 1959.

FOLGADO, Segundo. Cristocentrismo teológico. In: Fr. Luis de León. Madrid: El Escorial, 1968.

GARCÍA, Jaime. La paz, un camino hacia Dios: fray Luis de León maestro de vida espiritual. Madrid, Agustiniana, 2013.

GEORGE, Robert P. Kelsen y Santo Tomás sobre la doctrina de la ley natural. Persona y Derecho, n. 42, 2000.

GIRÓN-NEGRÓN, Luis. Your Dove-Eyes among Your Hairlocks: Language and Authority in Fray Luis de León's Respuesta que Desde su Prisión da a sus Émulos. Renaissance Quarterly, vol. 54 n. 4, 2001.

GONZÁLEZ, Adolfo. Reforma luterana y tradición católica. Salamanca: Publicaciones Universidad Pontificia, 1987.

GUY, Alain. El eclecticismo de fray Luis de León. GARCÍA DE LA CONCHA, Víctor; SAN JOSÉ LERA, Javier (Ed.). Fray Luis de León. Historia, Humanismo y Letras. Salamanca: Eusal, 1996.

GUY, Alain. La pensée de Fray Luis de León. Contribution à l'étude de la philosophie espagnole au XVIe siècle. París: Vrin, 1943.

GUZMÁN BRITO, Alejandro. El derecho como facultad en la Neoescolástica española del siglo XVI. Madrid: Iustel, 2009.

HERRERA, Rosa María. La etimología de lex en el tratado De Legibus de fray Luis de León. La ciudad de Dios, n. 204, 1991. 
HERVADA, Javier. Esencia del matrimonio y consentimiento matrimonial. In: Escritos de derecho natural. Pamplona: Eunsa, 1986.

KAMEN, Henry. La Inquisición española. Una revisión histórica. Barcelona: Crítica, 1988. KOTTMAN, Karl A. Fray Luis de León O.S.A. Notebook on the Promises of the Law. Augustiniana, vol. 22 n. 1-2, 1972.

KOTTMAN, Karl A. Law and Apocalypse: The Moral Thought of Luis de León (1527?1591). La Haya: Martinus Nijhoff, 1972.

LAZCANO, Rafael. Fray Luis de León: bibliografía. Madrid: Agustiniana, $1994^{2}$.

LEINSLE, Ulrich G. Introduction to Scholastic Theology. Washington DC: The Catholic University of America Press, 2010.

LÓPEZ, Abilio. La idea cristocéntrica en Fray Luis de León. Religión y Cultura, vol. 6 n. 23-24, 1961.

MOLINA, Enrique. La moral entre la convicción y la utilidad. La evolución de la moral desde la manualística al proporcionalismo y al pensamiento de Grisez-Finnis. Pamplona: Eunate, 1996.

MONREAL, Juan Luis. Fray Luis de León, filólogo de la teología. Archivum. Revista de la Facultad de Filología, n. 60, 2010.

MORREALE, Margherita. Luis de León: Breve storia delle edizioni e problemi attinenti. Cultura Neolatina, n. 58, 1998.

NAVARRO, Hipólito. Expositio in Genesim de fray Luis de León. Pamplona: Universidad de Navarra, tesis de doctorado, 1988.

PACHECO, Francisco. Libro de descripción de verdaderos retratos de ilustres y memorables varones (1599). Sevilla: Disputación Provincial, 1985.

PAGDEN, Anthony. The Preservation of Order: The School of Salamanca and the Ius Nature. In: HODCROFT, Frederick William (Ed.). Medieval and Renaissance Studies on Spain and Portugal in Honour of P. E. Russell. Oxford: The Society for the Study of Medieval Languages and Literature, 1981.

PENA, Miguel-Anxo. La Escuela de Salamanca. De la Monarquía hispánica al Orbe católico. Madrid: BAC, 2009.

PENA, Miguel-Anxo. Derecho natural y ley natural en las Indias. La propuesta de Vitoria. Laurentianum, n. 49, 2008.

PEREIRA, Carolina. La autoridad del derecho. Un diálogo con John M. Finnis. Granada: Comares, 2008.

PEREÑA, Luciano. La Escuela de Salamanca. El legado de paz de Francisco de Vitoria. Madrid: Universidad Francisco de Vitoria, 2002.

PEREÑA, Luciano. La Escuela de Salamanca y la duda indiana. In: VV.AA. Francisco de Vitoria y la Escuela de Salamanca. La ética de la conquista de América. Madrid: CSIC, 1984. 
PEREÑA, Luciano. La tesis de la coexistencia pacífica en los teólogos clásicos españoles. Madrid: Instituto de Estudios León XIII, 1963.

PEREÑA, Luciano. Diego de Covarrubias y Leyva, Maestro del Derecho Internacional. Madrid: CSIC, 1957.

PEREÑA, Luciano. El descubrimiento de América en las obras de fray Luis de León. Revista Española de Derecho Internacional, n. 8, 1955.

PÉREZ, Joseph. Fray Luis de León y el humanismo. Madrid: Gadir, 2013.

PRODI, Paolo. Una historia de la justicia. De la pluralidad de fueros al dualismo moderno entre conciencia y derecho. Buenos Aires: Katz, 2008.

RAMÍREZ, Santiago. El derecho de gentes. Examen crítico de la filosofía del derecho de gentes desde Aristóteles hasta Francisco Suárez. Buenos Aires-Madrid: Studium, 1955.

RAZ, Joseph. Razón práctica y normas. Madrid: CEPC, 1991.

RODRIGUES, Manuel Augusto. Ecos da exegese judaica medieval nas obras bíblicas de Fr. Luis de león, Fr. Luís de Sotomaior e Fr. Heitor Pinto. SOTO, José María (Coord.). Pensamiento medieval hispano. Homenaje a Horacio Santiago-Otero. Madrid: CSIC, 1998.

RODRÍGUEZ, José. Fray Luis de León, canonista (manuscrito inédito De Symonia). Anuario jurídico y económico escurialense, n. 28, 1995.

SEELMANN, Kurt. Selbstherrschaft, Herrschaft über die Dinge und individuelle Rechte in der Spanischen Spätscholastik. In: KAUFMANN, Matthias; SCHNEPF, Robert (Ed.). Politische Metaphysik. Die Entstehung moderner Rechtskonzeptionen in der Spanischen Scholastik. Frankfurt: Peter Lang, 2007.

SEELMANN, Kurt. Teologia e giurisprudenza alle soglie della Modernità. La nascita del moderno diritto naturale nella tarda scolastica ibérica. Materiali per una storia della cultura giuridica moderna, vol. 29 n. 2, 1999.

THOMPSON, Colin P. The lost works of Luis de León (1) De Simonia. Bulletin of Hispanic Studies, vol. 57 n. 2, 1980.

THOMPSON, Colin P. La lucha de las lenguas. Fray Luis de León y el Siglo de oro en España. Salamanca: Junta de Castilla y León, 1995.

TIERNEY, Brian. L'idea dei diritti naturali. Diritti naturali, legge naturale e diritto canonico 1150-1625. Bolonia: Il Mulino, 2002.

VÁZQUEZ, Juan José. El pensamiento jurídico de fray Luis de León. Nueva Etapa, n. 57, 1991.

VEGA, Ángel Custodio. Fray Luis de León. In: DÍAZ-PLAJA, Guillermo (Dir.). Historia general de las literaturas hispánicas. Barcelona: Barna, 1951.

Submissão em: 11/08/2013

Aceito em: 11/12/2013: 